Indexed by

\title{
Scopus'
}

\section{EXPERIMENTAL STUDY OF INFLUENCE OF FINE DROP MOISTURE AND CONTAMINANTS IN HEAT CARRIER ON COEFFICIENT OF HEAT REMOVAL OF VORTEX HEAT EXCHANGER OF GAS CONTROL STATION HEATING SYSTEM}

\begin{tabular}{|c|c|}
\hline & $\begin{array}{l}\text { Ekaterina Gennadievna } \\
\text { Pakhomova }\end{array}$ \\
\hline DAD $\equiv$ & $\begin{array}{l}\text { Southwest State University, } \\
\text { Faculty of Construction and } \\
\text { Architecture, Department of } \\
\text { Industrial and Civil Construc- } \\
\text { tion, } \\
\text { Kursk, Russian Federation }\end{array}$ \\
\hline & $\begin{array}{l}\text { Semicheva Natalia } \\
\text { Evgenievna }\end{array}$ \\
\hline oogle & $\begin{array}{l}\text { Southwest State University, } \\
\text { Faculty of Construction and } \\
\text { Architecture, Department of } \\
\text { Heat, Gas and Water Supply, } \\
\text { Kursk, Russian Federation }\end{array}$ \\
\hline
\end{tabular}

\author{
Grigorova Natalia Pavlovna \\ Southwest State University, \\ Faculty of Construction and \\ Architecture, Department of \\ Heat, Gas and Water Supply, \\ Kursk, Russian Federation
}

\author{
Monastyrev Pavel \\ Vladislavovich \\ Tambov State Technical Uni- \\ versity, Institute of Architecture, \\ Construction and Transport, \\ Department of Urban Construc- \\ tion and Motorways, \\ Tambov, Russian Federation
}

Key words: controlled pressure drop, thermodynamic stratification, vortex heat exchanger, heating system

doi:10.5937/jaes18-27798

Cite article:

Pakhomova, G. E., Pavlovna, N. G., Vladislavovich, P. M., \& Evgenievna, N. S. [2020]. Experimental study of influence of fine drop moisture and contaminants in heat carrier on coefficient of heat removal of vortex heat exchanger of gas control station heating system. Journal of Applied Engineering Science, 18(3), 427 - 431.

Online aceess of full paper is available at: www.engineeringscience.rs/browse-issues 


\title{
EXPERIMENTAL STUDY OF INFLUENCE OF FINE DROP MOISTURE AND CONTAMINANTS IN HEAT CARRIER ON COEFFICIENT OF HEAT REMOVAL OF VORTEX HEAT EXCHANGER OF GAS CONTROL STATION HEATING SYSTEM
}

\author{
Ekaterina Gennadievna Pakhomova ${ }^{1 *}$, Grigorova Natalia Pavlovna ${ }^{2}$, Monastyrev Pavel Vladislavovich ${ }^{3}$, \\ Semicheva Natalia Evgenievna ${ }^{2}$ \\ ${ }^{1}$ Southwest State University, Faculty of Construction and Architecture, Department of Industrial and \\ Civil Construction, Kursk, Russian Federation \\ ${ }^{2}$ Southwest State University, Faculty of Construction and Architecture, Department of Heat, Gas and \\ Water Supply, Kursk, Russian Federation \\ ${ }^{3}$ Tambov State Technical University, Institute of Architecture, Construction and Transport, Department of \\ Urban Construction and Motorways, Tambov, Russian Federation
}

Experimental studies of fine drip moisture and contaminants influence in the heat carrier on the heat transfer coefficient in the vortex heat exchanger of the heating system of gas control room were described. Pilot studies were carried out in two stages.

At the first stage, the test values of coolant temperature decrease were analyzed due to heat removal for evaporation and heat transfer coefficient under idealized conditions without taking into account the effect of fine moisture and contaminants on the process of heat transfer to the blades in the vortex heat exchange apparatus.

At the second stage, the heat transfer coefficient was studied under conditions close to actual operating conditions of vortex heat exchange element, when fine moisture and specific contaminants are in the natural gas which is in contact with water.

As a result of the first stage of experimental studies, it was found that experimental values of heat carrier temperature decrease due to heat extraction for liquid evaporation on the surface of swirling swirler blade in vortex heat exchanger are slightly different from those determined theoretically. And they mainly decrease.

Analysis of the heat transfer coefficient values under idealized conditions, obtained experimentally and calculated theoretically, shows their satisfactory convergence. This convergence is measurement error and data calculation. As a result of the second stage of pilot studies it was revealed that availability of disperse moisture increases heat transfer coefficient in 1,4 $\div 1,9$ times. There is evaporation temperature increase as the concentration of contaminants bombarding the mirror of liquids increases. This fact also intensifies heat exchange process.

Thus, as a result of experimental studies, the possibility of using a vortex heat exchange apparatus in a heating system of gas control station has been confirmed.

Key words: controlled pressure drop, thermodynamic stratification, vortex heat exchanger, heating system

\section{INTRODUCTION}

The relevance of energy saving and environmental safety issues in the construction and operation of buildings for various purposes is no doubt [1, 2, 3, 4, 5]. This also applies to small production buildings. For example, a feature of gas control station operation is gas pressure control which is coming from the line to consumers. It is necessary to install pressure regulators for this purpose. These regulators should operate at a sufficiently high difference of input and output pressure values (from 3.5 and more times) with unclaimed repayment of excess energy.

The use of a significant potential of pressure drop energy between natural gas pipelines $[6,7]$ is possible when using a vortex heat exchanger, which can be used as an element of the heating system of gas distribution room.
Such heating method of this room heating makes it possible to avoid installation of autonomous sources of heat energy, which allows to reduce fuel costs, reduce emissions of pollutants into the environment, as well as to provide more comfortable operating conditions of pressure regulator due to difference reduction of controlled gas pressure supplied to the consumer.

The process of heat exchange in vortex heat exchange apparatus at the flow of twisted gas flow is characterized by two sections (at the inlet and outlet of the swirler in heat exchange apparatus). At swirler inlet flow structure and patterns of heat and mass exchange are determined depending on method and intensity of initial swirling of heat carrier.

The process of heat exchange during swirling of gas flow in the form of ideal gas in the swirler is studied in details 
$[8,9,10,11,12]$. However, under real conditions, swirling gas is always saturated with moisture and contaminants.

As heat carrier moves from inlet to outlet sections of swirler made in the form of converging nozzle, concentration of phase particles of moisture and contaminants is redistributed to periphery of twisted flow of natural gas. This leads to an increase in adhesion frequency of the separate liquid particles and contaminants, their consolidation, as well as to a sharp activation of both impact and sliding contacts with narrowing surface. As a result, there is a random distribution of evaporation heat on the heat exchange surface. This makes it difficult to form mathematical model to determine the amount of increase in heat transfer coefficient characterizing the degree of heat transfer intensity. This issue can only be solved using experimental studies of changes in evaporation temperature at different flow parameters of heat carrier, as well as change in heat transfer coefficient on swirler blades in vortex heat exchanger when there is fine drop moisture and specific contaminants in heat carrier.

\section{MATERIALS AND METHODS}

Experimental study of heat exchange process on swirler blades in vortex heat exchange apparatus under the influence of fine drop moisture and contaminants was carried out in two stages.

At the first stage, analysis of experimental values of coolant temperature decrease was carried out due to heat extraction for liquid evaporation on the surface of swirling blade of swirler and coefficient of heat removal in vortex heat exchange apparatus. This study was conducted under idealized conditions where no contamination was present in natural gas in contact with water. Such an experiment was necessary to determine heat transfer medium temperature and heat transfer coefficient at the outlet of the swirler in vortex heat exchange apparatus without taking into account an effect of fine drop moisture and contaminants in heat transfer medium on swirler blades.

At the second stage, heat transfer coefficient was studied under conditions close to actual operating conditions of vortex heat exchange element, when fine moisture and specific contaminants are present in natural gas in contact with water. This experiment makes it possible to simulate real conditions of vortex heat exchanger operation in work room of gas control station.

Experimental research was carried out at a laboratory plant simulating heating element of heating system of an industrial building - gas control station.

Figure 1 shows schematic diagram of the experimental installation.

\section{RESULTS}

As a result of the first stage of this experimental study, it was found that experimental values of coolant temperature decrease due to heat extraction for liquid evaporation on the surface of swirling swirler blade in vortex heat exchanger are slightly different from those proved theoretically. These values mainly decrease (Table 1).

It was necessary to maintain initial temperature, relative humidity of heat carrier under study and to saturate it with fine moisture in order to measure heat transfer coefficient. This was done in climate chamber by a nozzle. Experimentally obtained heat transfer coefficient values were averaged (for four experiments). Table 2 shows these values.

Analysis of heat transfer coefficient values, obtained

Table 1: Parameters of the analysed coolant on swirler blades of vortex heat exchanger

\begin{tabular}{|c|c|c|c|c|c|c|c|c|c|c|}
\hline \multirow{2}{*}{ 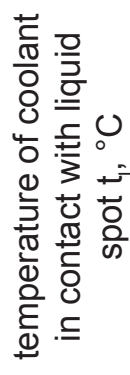 } & \multirow[b]{2}{*}{ 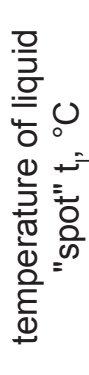 } & \multirow[b]{2}{*}{ 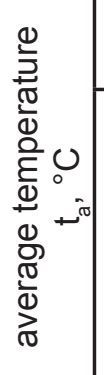 } & \multicolumn{3}{|c|}{$\begin{array}{l}\text { Pressure under the } \\
\text { swirler blade }\end{array}$} & \multicolumn{2}{|c|}{$\begin{array}{c}\text { Concentration of } \\
\text { water vapor }\end{array}$} & \multirow[b]{2}{*}{ 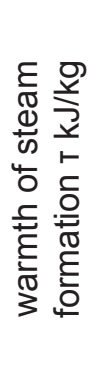 } & \multicolumn{2}{|c|}{$\begin{array}{l}\text { evaporation } \\
\text { temperature }\end{array}$} \\
\hline & & & 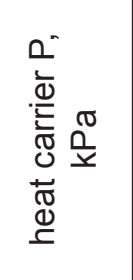 & 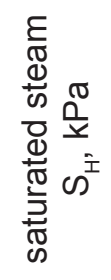 & 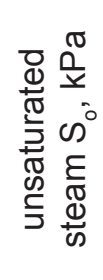 & 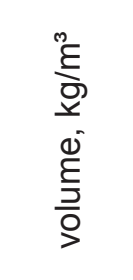 & 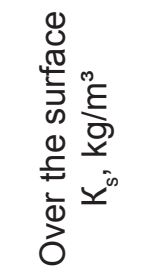 & & 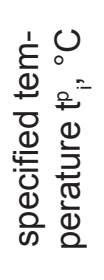 & 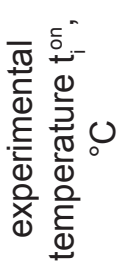 \\
\hline 0 & 2,0 & 1,0 & 991,02 & 7,15 & 6,11 & 0,0048 & 0,0056 & 2494 & 0,8 & 1,2 \\
\hline 5 & 7,0 & 6,0 & 984,40 & 10,44 & 8,72 & 0,0068 & 0,0078 & 2484 & 2,4 & 2,5 \\
\hline 10 & 13,0 & 11,5 & 987,64 & 15,13 & 12,27 & 0,0094 & 0,0115 & 2461 & 7,5 & 7,6 \\
\hline 15 & 18,0 & 16,5 & 990,06 & 20,84 & 17,04 & 0,0129 & 0,0155 & 2457 & 12,4 & 12,4 \\
\hline 20 & 23,0 & 21,5 & 989,30 & 26,63 & 23,37 & 0,0173 & 0,0194 & 2445 & 17,4 & 17,8 \\
\hline 25 & 27,0 & 26,0 & 991,08 & 38,11 & 31,67 & 0,0230 & 0,01275 & 2436 & 21,2 & 21,3 \\
\hline 30 & 33,0 & 31,5 & 988,60 & 47,93 & 42,41 & 0,0303 & 0,0339 & 2421 & 27,3 & 27,6 \\
\hline 40 & 37,0 & 36,5 & 993,75 & 63,23 & 56,22 & 0,0395 & 0,0442 & 2402 & 32,3 & 33,2 \\
\hline 45 & 42,0 & 41,0 & 989,84 & 81,98 & 73,75 & 0,0510 & 0,0563 & 2398 & 37,2 & 37,8 \\
\hline
\end{tabular}




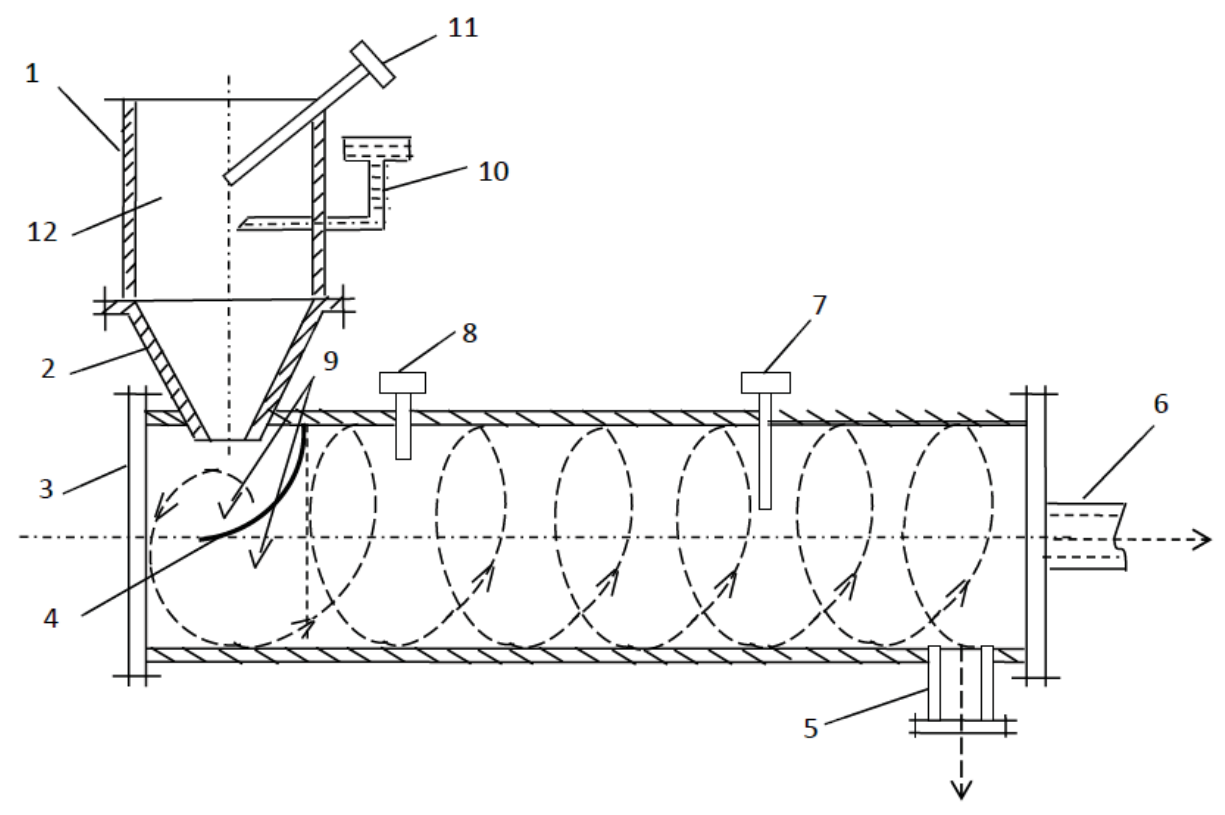

Figure 1: Experimental installation of vortex heat exchanger: 1- heat carrier supply branch pipe; 2 - tapering nozzle; 3 - vortex heat exchanger housing; 4 - swirling blade of the swirler; 5 - hot flow outlet branch pipe; 6 - cold flow outlet branch pipe; 7 - shell of a cold flow liquid thermometer sleeve; 8 - shell of a hot flow liquid thermometer sleeve; 9 - differential thermocouple; 10 - humidifier; 11 - sleeve of liquid thermometer of inlet branch pipe; 12 - climate chamber.

experimentally and calculated theoretically, shows their satisfactory convergence. This convergence is in measurement error and data calculation. This happens at idealization of wet coolant and "spot" of liquid without taking into account chemical and physical state of coolant in real conditions of gas supply to consumers.

Theoretically expected (solid line curve) and experimentally obtained (dashed line curve) change of heat transfer coefficient under the "spot" of liquid on the surface of swirler blade was defined for specified flow rate, measured coolant temperatures, coolant pressure and relative humidity (Figure 2).

As a result, it was revealed that fine moisture bombards the "spot" of liquid and as a result, due to those liquid particles that are ripped out when the fine moisture hits its "spot" on the surface of the swirler blade, there is a random distribution of evaporation heat in boundary layer above the "spot" of liquid.

Therefore, the presence of fine moisture in the heat carrier stream intensifies heat exchange of evaporation, which leads to pulsating change in the heat transfer coefficient, wherein the distribution of pulsations in boundary layer of the "spot" of liquid depends along with temperature and on saturation of the heat carrier with drip moisture.

Note: mass flow of coolant $\mathrm{G}, \mathrm{kg} / \mathrm{s}$; diameter of "spot"

Table 2: Comparative characteristic of test and design values of heat transfer coefficient on the surface of the swirler blade of vortex heat exchanger

\begin{tabular}{|c|c|c|c|c|c|c|c|c|}
\hline 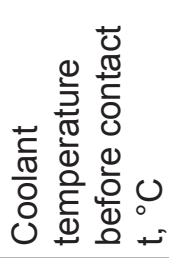 & 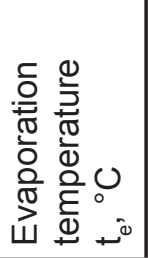 & 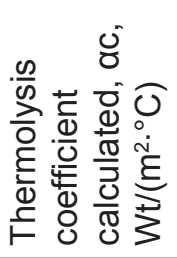 & 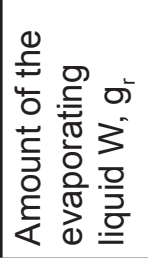 & 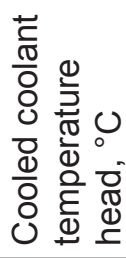 & 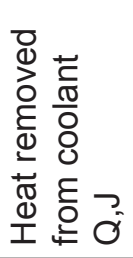 & 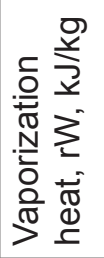 & 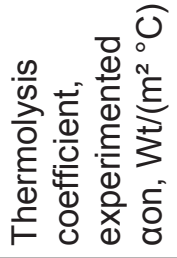 & 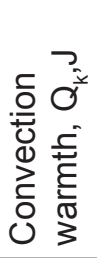 \\
\hline 5 & 5,2 & 48,35 & 8,4 & 0,68 & 6,807 & 5,823 & 48,35 & 0,984 \\
\hline 10 & 10,2 & 48,40 & 8,6 & 0,69 & 6,907 & 5,913 & 48,85 & 0,994 \\
\hline 15 & 15,6 & 48,34 & 8,8 & 0,69 & 6,407 & 6,017 & 49,22 & 0,890 \\
\hline 20 & 20,3 & 48,33 & 8,8 & 0,70 & 7,007 & 6,055 & 49,56 & 0,953 \\
\hline 25 & 25,3 & 48,30 & 9,1 & 0,71 & 7,107 & 6,153 & 49,65 & 0,954 \\
\hline 30 & 30,4 & 48,27 & 8,9 & 0,69 & 6,907 & 6,008 & 49,72 & 0,899 \\
\hline 35 & 35,4 & 48,19 & 8,8 & 0,69 & 6,807 & 9,905 & 49,86 & 0,902 \\
\hline 40 & 40,2 & 48,00 & 9,0 & 0,70 & 7,707 & 5,992 & 49,90 & 1,015 \\
\hline
\end{tabular}


of liquid $d_{n}=0.12 \mathrm{~m}$; heat carrier thermal capacity, $C_{v, g}=1.05 \mathrm{~kJ} / \mathrm{kg}$; average density $1.44 \mathrm{~kg} / \mathrm{m}^{3}$.

The research of fine moisture impact process on thermolysis coefficient in vortex heat exchanger at various temperature conditions showed that availability of disperse moisture up to $6 \mathrm{~g} / \mathrm{m}^{3}$ (match up the intake of natural gas from main gas pipelines into gas control point) increases thermolysis coefficient in $1,4 \div 1,9$ times. Heat transfer coefficient also increases as temperature of heat carrier entering vortex heat exchanger increases. This happens due to the decrease in the surface tension of the "spot" of liquid.

Then experimental studies on intensification of heat removal coefficient of heat carrier in contact with "spot" of liquid on the surface of swirler blade at its bombardment with dispersed contaminants were carried out.

Heat transfer coefficient increases to the maximum value at $d_{r}=3 \mathrm{~g} / \mathrm{m}^{3}$ when there are contaminants. Then it falls a little and at a weight of $5 \mathrm{~g} / \mathrm{m}^{3}$ remains constant. This process is shown on Figure 3.

This complexity of the change in heat transfer coefficient is explained by the following.

Increasing mass of contaminants together with changing area increases time interval of evaporation process by volume of boundary layer. There is surface process of evaporation by diameter of "spot" of liquid and spectral process of evaporation by volume of boundary layer. This is a result of contact of "spot" of liquid with heat carrier.

If contamination in the heat carrier is more than $4 \mathrm{~g} / \mathrm{m}^{3}$, only a surface evaporation process is observed, because the thickness of the "spot" of the liquid is commensurate with a boundary layer on swirler blades. This minimizes the effect of volume evaporation, because part of the liquid is demolished by the heat carrier flow into the inside of vortex tube housing.

The following facts are defined during the experimental

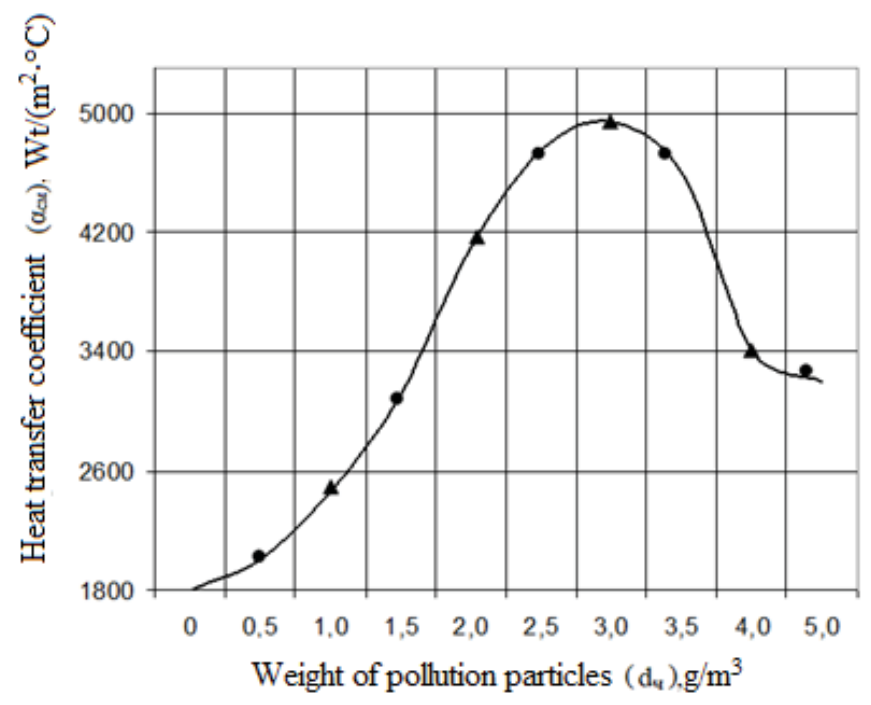

Figure 2: Heat exchange on swirler blades of vortex heat exchanger study of changes in heat-and mass exchange above the contact surface of the "spot" of the liquid in continuous fixation of the evaporation temperature by the automatic potentiometer KSP-4-10.

The evaporation temperature increases with pulse bursts as the concentration of contaminants that bombard the mirror of liquids increases. This is due to probability-random ingress of evaporating drops of moisture on differential thermo steam.

Therefore, there is confirmation of theoretical prerequisites for intensification of cooling process of heat carrier in contact with liquid during bombing of condensate spot mirror by specific contamination of pipelines.

\section{CONCLUSIONS}

Experimental study of fine drip moisture influence and specific contaminants in heat carrier on heat transfer coefficient on swirler blades in vortex heat exchange apparatus of heating system in gas control station was carried out. It is stated that availability of disperse moisture increases thermolysis coefficient in $1,4 \div 1,9$ times. Heat transfer coefficient also increases as the temperature of the heat carrier entering the vortex heat exchanger increases. This happens due to the decrease in the surface tension of the "spot" of liquid.

Evaporation temperature increases with pulse bursts as the concentration of contaminants bombarding the mirror of liquids increases. This is due to probability-random ingress of evaporating drops of moisture on differential thermo steam.

Therefore, there is confirmation of theoretical prerequisites for intensification of cooling process of heat carrier in contact with liquid when bombing the condensate spot mirror by specific contaminations of pipelines.

Analysis of laboratory-industrial study of thermodynamic stratification of natural gas in elements of vortex heat exchange device confirms legality of obtained scientific provisions of heat-moisture treatment of heat carrier in conditions of its pressure decrease before natural gas supply to consumers. It also confirms possibility of using vortex heat exchange device in heating system of gas control stations.

It can be stated that the use of vortex heat exchanger in heating system of gas control station will allow to save natural gas as fuel in heating system of gas control station, eliminating the need to install autonomous water heaters, in which water heating is carried out by gas combustion; provide more comfortable operating conditions of pressure regulator due to reduction of variable pressure difference of gas supplied to the consumer, as there is a significant decrease in output pressure due to operation of vortex pipe as a heat exchanger of the heating system in buildings. 


\section{REFERENCES}

1. Dubrakova, O. K. [2019]. Optimization of thermal modernization of a group of buildings using simulation modeling. Journal of Applied Engineering Science, 17(2), 192-197.

2. E. Mishchenko, P. Monastyrev and O. Evdokimtsev. Quality Improvement of Specialists Training for Energy-Efficient Construction. 2018 IOP Conf. Ser.: Mater. Sci. Eng. 463032046 https://doi. org/10.1088/1757-899X/463/3/032046

3. Erofeev A.V., Yartsev V.P., Monastery P.V. Decorative and protective plates for facade finishing of buildings//News of higher educational institutions. Technology of the textile industry. 2017. № 1 (367). Pages 101-104.

4. Gusev B.V., Yezersky V.A., Monastery P.V. Thermal conductivity of mineral wool boards in operational conditions//Industrial and civil construction. - 2005. - № 1. - C.48-49.

5. Gusev B.V., Yezersky V.A., Monastery P.V. Changing the linear dimensions of mineral wool boards in operational conditions//Industrial and civil construction. - 2004. - № 8. - Pages.32-34.

6. Patent 2615878 Russian Federation: MPC F 28 D 7/10. Vortex heat exchange element/Kobelev N.S., Grigorov N.P. [et al]; Applicant and patent holder Kursk state technical university. No. 2016110870; publ. 11.04.2017. Bul. № 11.
7. Patent 2622340 Russian Federation: MPC F 28 D 7/10. Vortex heat exchange element/Kobelev N.S., Grigorov N.P. [et al]; Applicant and patent holder Kursk state technical university. No. 2016128870953; publ. 14.06.2017, Bul. № 17.

8. Exhaust air heat recovery systems in public buildings and structures: Typical design materials. 90402-24.86/Kiev: CNMIEP of engineering equipment, 1988. 98 pages.

9. Goldschtik, M.A. Vortex Flows [Text]/M.A. Goldschtik. Novosibirsk: Science, 1981. 336 pages.

10. Kolyshev, N.D. Study of heat transfer in the working space of the vortex pipe with diffuser/N.D. Kolyshev, N.I. Orodnikov//works of Kuibevsky aviation in-th. 1979. Issue 37.

11. Ovchinnikov, A.A. Study of hydroaerodynamic patterns in vortex mass exchange by tangential swirlers. Abstract of thesis /A.A. Ovchinnikov. Kazan, 1973. 24 pages.

12. Lapkevich, V.I. Intensification of heat collection in pipes with internal screw finning/V.I. Lapkevich, N.I. Perepelica, A.P. Sapankevich//Heat power engineering. 1980. №6. Pages 22-24. 